\title{
BMJ Open Interventions to combat or prevent drug counterfeiting: a systematic review
}

\author{
Fadi El-Jardali, ${ }^{1,2,3}$ Elie A Akl, ${ }^{1,3,4,5}$ Racha Fadlallah, ${ }^{1}$ Sandy Oliver, ${ }^{6}$ \\ Nadine Saleh, ${ }^{7}$ Lamya El-Bawab, ${ }^{1}$ Rana Rizk, ${ }^{8}$ Aida Farha, ${ }^{9}$ Rasha Hamra ${ }^{10}$
}

To cite: El-Jardali F, AkI EA, Fadlallah $\mathrm{R}$, et al. Interventions to combat or prevent drug counterfeiting: a systematic review. BMJ Open 2015;5:e006290. doi:10.1136/bmjopen-2014006290

- Prepublication history and additional material is available. To view please visit the journal (http://dx.doi.org/ 10.1136/bmjopen-2014006290).

Received 2 August 2014 Revised 9 December 2014 Accepted 22 December 2014

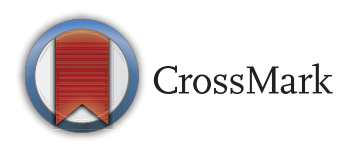

For numbered affiliations see end of article.

Correspondence to Dr Fadi El-Jardali; fe08@aub.edu.Ib

\section{ABSTRACT}

Objective: Drug counterfeiting has serious public health and safety implications. The objective of this study was to systematically review the evidence on the effectiveness of interventions to combat or prevent drug counterfeiting.

Data sources: We searched multiple electronic databases and the grey literature up to March 2014. Two reviewers completed, in duplicate and independently, the study selection, data abstraction and risk of bias assessment.

Study eligibility criteria, participants and interventions: We included randomised trials, non-randomised studies, and case studies examining any intervention at the health system-level to combat or prevent drug counterfeiting. Outcomes of interest included changes in failure rates of tested drugs and changes in prevalence of counterfeit medicines. We excluded studies that focused exclusively on substandard, degraded or expired drugs, or that focused on medication errors.

Appraisal and synthesis: We assessed the risk of bias in each included study. We reported the results narratively and, where applicable, we conducted metaanalyses.

Results: We included 21 studies representing 25 units of analysis. Overall, we found low quality evidence suggesting positive effects of drug registration (OR=0.23; $95 \% \mathrm{Cl} 0.08$ to 0.67 ), and WHOprequalification of drugs $(\mathrm{OR}=0.06 ; 95 \% \mathrm{Cl} 0.01$ to 0.35 ) in reducing the prevalence of counterfeit and substandard drugs. Low quality evidence suggests that licensing of drug outlets is probably ineffective (OR=0.66; $95 \% \mathrm{Cl} 0.41$ to 1.05$)$. For multifaceted interventions (including a mix of regulations, training of inspectors, public-private collaborations and legal actions), low quality evidence suggest they may be effective. The single RCT provided moderate quality evidence of no effect of 'two extra inspections' in improving drug quality.

Conclusions: Policymakers and stakeholders would benefit from registration and WHO-prequalification of drugs and may also consider multifaceted interventions. Future effectiveness studies should address the methodological limitations of the available evidence.

Trial registration number: PROSPERO CRD42014009269.

\section{Strengths and limitations of this study}

- This is the first systematic review assessing the effectiveness of interventions to combat or prevent drug counterfeiting.

- The systematic review responds to a policyrelevant priority identified by policymakers and stakeholders from several low-income and middle-income countries.

- We searched multiple databases and included published as well as grey literature.

- Most of the included studies were observational in nature.

\section{INTRODUCTION}

Drug counterfeiting is widespread and affects developing as well as developed countries. $^{1}{ }^{2}$ It is believed that up to $10 \%$ of all medicines sold worldwide are counterfeit, with higher prevalence in regions where drug regulatory and enforcement systems are weakest. ${ }^{3} 4$ Estimates suggest that counterfeited drugs can account for over $30 \%$ of all drugs in parts of Africa, Asia and the Middle East, in contrast to less than $1 \%$ in the USA and Western Europe. ${ }^{4-6}$

There is still no consensus over what constitutes a counterfeited medicine. ${ }^{1}{ }^{7}$ The WHO defined counterfeit medicines as those which have been deliberately and fraudulently mislabelled with respect to identity and/or source; counterfeit medicines may include medicines with the correct ingredients or with the wrong ingredients, without active ingredients, with insufficient active ingredients or with fake packaging. ${ }^{2}$ Under the Trade-Related Aspects of Intellectual Property Rights (TRIPS) Agreement, counterfeiting refers to the deliberate infringement of trademark on a commercial scale. ${ }^{78}$ This definition, however, diverts attention from the serious public health implications of poor-quality drugs. ${ }^{8} 9$ Thus, the term 'falsified' is increasingly being used as a synonym for counterfeit drugs to avoid the controversy over Intellectual Property issues. ${ }^{9}$ 
Counterfeit and substandard drugs have often been conflated, ${ }^{9}$ with the latter referring to genuine medicines that have failed to meet the quality specifications set by national pharmacopoeia standards. ${ }^{2}$ In 2011 , the WHO member states incorporated counterfeit and substandard medicines under the new term "substandard/ spurious/falsely-labelled/falsified/counterfeit medical products" (SSFFC). ${ }^{10}$ This new term has recently been queried as it is felt not to adequately differentiate between the different illicit drug categories, which may entail different solutions. ${ }^{11}$

Counterfeited drugs span the spectrum from lifestyle drugs to lifesaving drugs. ${ }^{12}$ They can result in adverse health outcomes and treatment failures, development of drug resistance and decline in confidence in health systems, all of which contribute to the burden of disease and, subsequently, to excess morbidity and mortality. ${ }^{13}$ Indeed, significant deaths have been attributed to counterfeited medications. ${ }^{13-15}$

A variety of interventions have been recommended to combat the problem of drug counterfeiting. These include: legal actions and regulations on illicit traders, countermeasures using technologies, consumer education and cooperation with enforcement agencies. ${ }^{16}{ }^{17}$ The need to identify effective anticounterfeiting strategies has recently been raised as a main policy concern by policymakers from several low-income and middle-income countries including the Eastern Mediterranean Region. ${ }^{18}$ As a response, the Center for Systematic Review on Health Policy and Systems Research (SPARK) held a stakeholder meeting in Lebanon on January 2014 with 14 policymakers and stakeholders, including representatives from the Ministry of Public Health, Order of Pharmacy, order of physicians and practicing pharmacists. The members were engaged in framing the review question for the current systematic review.

The objective of this study was to systematically review the evidence on the effectiveness of interventions implemented to combat or prevent drug counterfeiting, particularly in low-income and middle-income countries, given its high priority and prevalence. We could not identify any systematic review in the literature that examined the effectiveness of interventions to combat drug counterfeiting. Thus, the findings can help inform policy-decisions regarding the type of interventions to implement, given their contexts and available resources.

\section{METHODS}

We developed a conceptual framework for the different anticounterfeiting strategies, informed by extensive review of the literature. The framework guided us in refining the review question and in developing the eligibility criteria. For details, please refer to figure 1 in the results section.

\section{Protocol and registration}

We registered the review protocol in PROSPERO International prospective register of systematic reviews. The protocol can be accessed at http://www.crd.york.ac. uk/PROSPERO/display_record.asp?ID=CRD42014009269.

\section{Eligibility criteria}

The eligibility criteria were:

Types of studies: Randomised trials, non-randomised studies (eg, cohort studies, prospective studies, retrospective studies, cross-sectional studies, before and after studies) and case studies. We excluded editorials, letters to the editors, reflections, proposals, reviews and studies published only in abstract format.

We considered published and unpublished studies.

Problem: Counterfeit/spurious/falsely-labelled/falsified/medicines.

We used the WHO's definition for counterfeit medicines, which includes medicines with the correct ingredients or with the wrong ingredients, without active ingredients, with insufficient active ingredients or with fake packaging drugs. ${ }^{2}{ }^{19}$ While the primary focus of our review is on counterfeit drugs, we included substandard drugs only when the study did not differentiate between the two or if it was unclear if the poor-quality medicine was counterfeit or substandard. However, we excluded studies that linked poor quality to degradation or
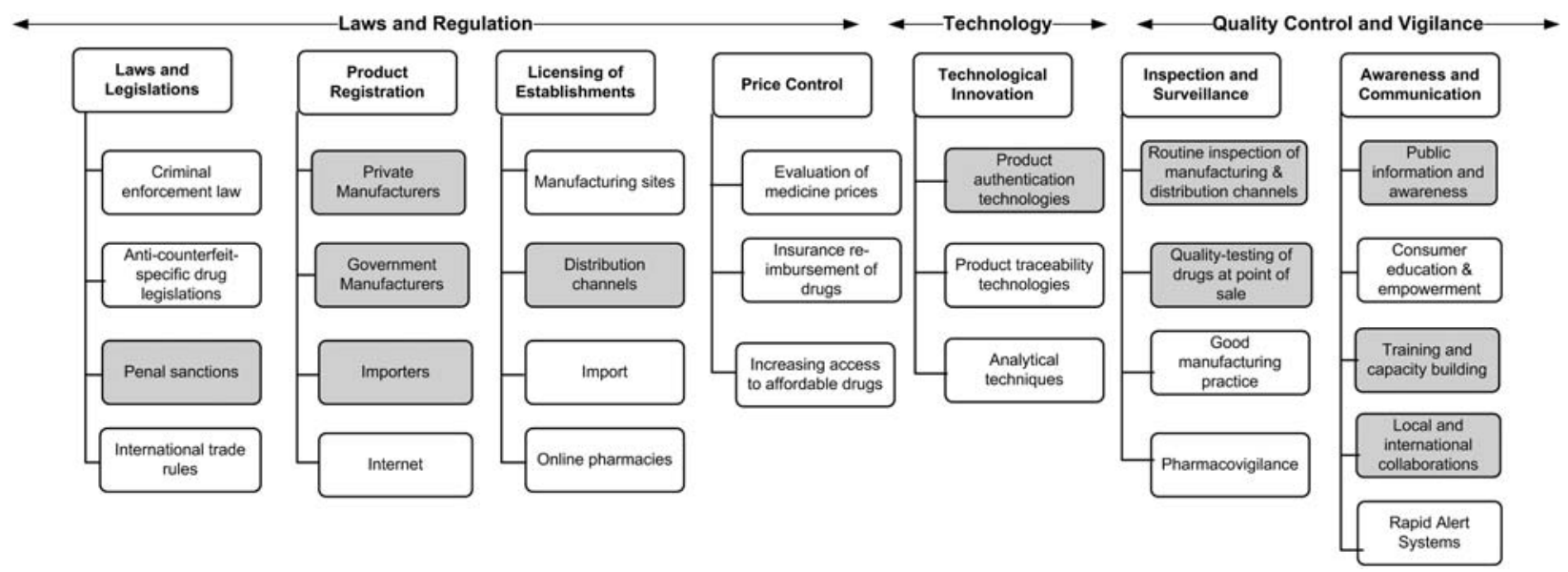

Figure 1 A framework for the different anticounterfeit drug strategies. 
expiration of drugs as these were beyond the scope of counterfeit drugs as per the WHO's definition. We also excluded studies that focused exclusively on substandard drugs and studies that focused on herbal medicines/ dietary supplements/cosmetics/food.

Types of interventions: We included any intervention at the health system level to combat or prevent drug counterfeiting (eg, anticounterfeit laws and legislations, inspection and quality control, awareness campaigns, technology). We excluded studies that focused on internet/online drug counterfeiting. We also excluded studies on the reliability of analytical techniques (eg, high-performance liquid chromatography and UV-visible spectrophotometry) and studies on interventions to improve the medication administration process or reduce medication errors.

Comparator/control: The comparator was the lack or absence of intervention, either explicitly or implicitly stated.

Type of outcome measures: Changes in failure rates of tested drugs (failure refers to drugs not meeting the minimum requirement for basic testing, quality control lab testing, and/or packaging analysis), changes in the prevalence of counterfeit/spurious/falsely-labelled/falsified/medicines, changes in quality of medicine, changes in behaviour of consumers, seizures of counterfeit drugs and closures of illegal outlets/warehouses/shops.

We did not exclude studies based on date of publication or setting. We excluded studies not published in English, Arabic or French.

\section{Literature search method}

We searched the following electronic databases up to March 2014: Medline, Pubmed, Embase, Cumulative Index to Nursing \& Allied Health Literature (CINAHL), Global Health Library, Rx for change, Cochrane Central Register of Controlled Trials (CENTRAL), Health Systems Evidence, Cab Direct, Academic Search Complete, Google Scholar, Mednar, GreylitNetwork and Opengrey.

The search combined various terms for counterfeit drugs and included free text words as well as controlled vocabulary terms such as MeSH (Medical Subject Headings), in addition to various search options available for each resource. We did not use any search filter for study type, language or date of publication. The search strategy was validated by a medical librarian who supports the work of the Center (see online supplementary appendix 1).

We also searched relevant websites such as the WHO, the Food and Drug Administration (FDA), the Center for Disease Control (CDC) and the US Pharmacopeia (USP). Also, we reviewed the reference lists of included studies and contacted the authors of relevant articles for further information or additional potentially relevant studies.

\section{Selection process}

Two reviewers screened the titles and abstracts of identified citations, in duplicate and independently, for potential eligibility. All reviewers hold at least a Master's degree (with some having PhDs) in public health or other health-related field and they have all been trained in conducting systematic reviews.

We conducted a calibration exercise to ensure validity of the selection process. We retrieved the full text for studies judged as potentially eligible by at least one of the two reviewers. Two reviewers screened the full texts in duplicate and independently for eligibility. They used a standardised and pilot tested screening form. They resolved disagreements by discussion.

\section{Data abstraction process}

Two reviewers abstracted data from eligible studies in duplicate and independently. They used a standardised data abstraction form to collect data on study design, definition, setting, drug type, intervention, comparison group, outcomes evaluated, statistical and non-statistical results, funding and reported conflicts of interests. They resolved disagreements by discussion.

\section{Risk of bias assessment}

Two reviewers independently assessed the risk of bias. They resolved disagreements by discussion. We used the Cochrane Risk of Bias tool to assess the risk of bias in randomised trials and a modified version of the Cochrane Risk of Bias tool to assess the risk of bias in non-randomised studies. $^{20}$ We graded each potential source of bias as low, high or unclear risk of bias.

\section{Data analysis and synthesis}

We calculated the $\kappa$ statistic to assess the agreement between the reviewers in judging full texts for eligibility. We conducted meta-analyses, stratified by the type of intervention. We calculated the unadjusted OR by entering the raw data in RevMan and planned a priori to pool the results using a random-effects model. The latter is recommended when heterogeneity between studies is assumed, particularly among observational studies. ${ }^{21}{ }^{22}$ We tested the results for homogeneity across studies using the $\mathrm{I}^{2}$ test and considered heterogeneity present if $\mathrm{I}^{2}$ was greater than $50 \%$. We also reported the results narratively when the data were not reported in a way to allow their inclusion in the meta-analysis.

\section{RESULTS}

The first two sections, respectively, provide an overview of the search results and a description of included studies, including their risk of biases. Afterwards the effects of the interventions are specifically addressed.

\section{Results of the search}

Figure 2 shows the study flow. Of the 10220 studies identified through database and website searches, 20 studies met our inclusion criteria. One additional study was identified through screening the reference lists of the included studies. The 21 included studies represented 
25 units of analysis (3 studies examined more than one type of strategy). We excluded 166 full texts (see online supplementary appendix 2 ). The value of $\kappa$ statistic for full-text screening was 0.638 , reflecting good agreement between the reviewers.

Online supplementary tables $\mathrm{S} 1$ and S2 show the characteristics of the included studies. The most common study design was cross-sectional (14/21). There were also five before-after studies, one retrospective study and one case study. Among the 21 included studies, we also identified 1 randomised trial that was conducted in parallel and on the same study population as 1 of the pre-post studies. ${ }^{23}$ Only one article was reported in French language. ${ }^{24}$ Sixteen articles were published in academic journals, three were reports from the WHO and two were reports from the USP. All studies were conducted in low-income and middle-income countries. However, none was from the Eastern Mediterranean Region.

Figure 1 shows the conceptual framework we developed for the different anticounterfeit interventions/ strategies. The shaded cells in the framework portray areas where evidence about the intervention exists. We could not establish whether evidence exists for counterfeit drugs bought online as this was beyond the scope of the review.

The 21 included studies examined various types of interventions (table 1). In all included studies, except the randomised trial, the comparator was the absence of intervention or strategy (explicitly or implicitly stated). For the randomised trial, two different levels of the intervention were compared to each other and to the absence of intervention. The types of outcomes measured were: changes in failure rates of tested drugs

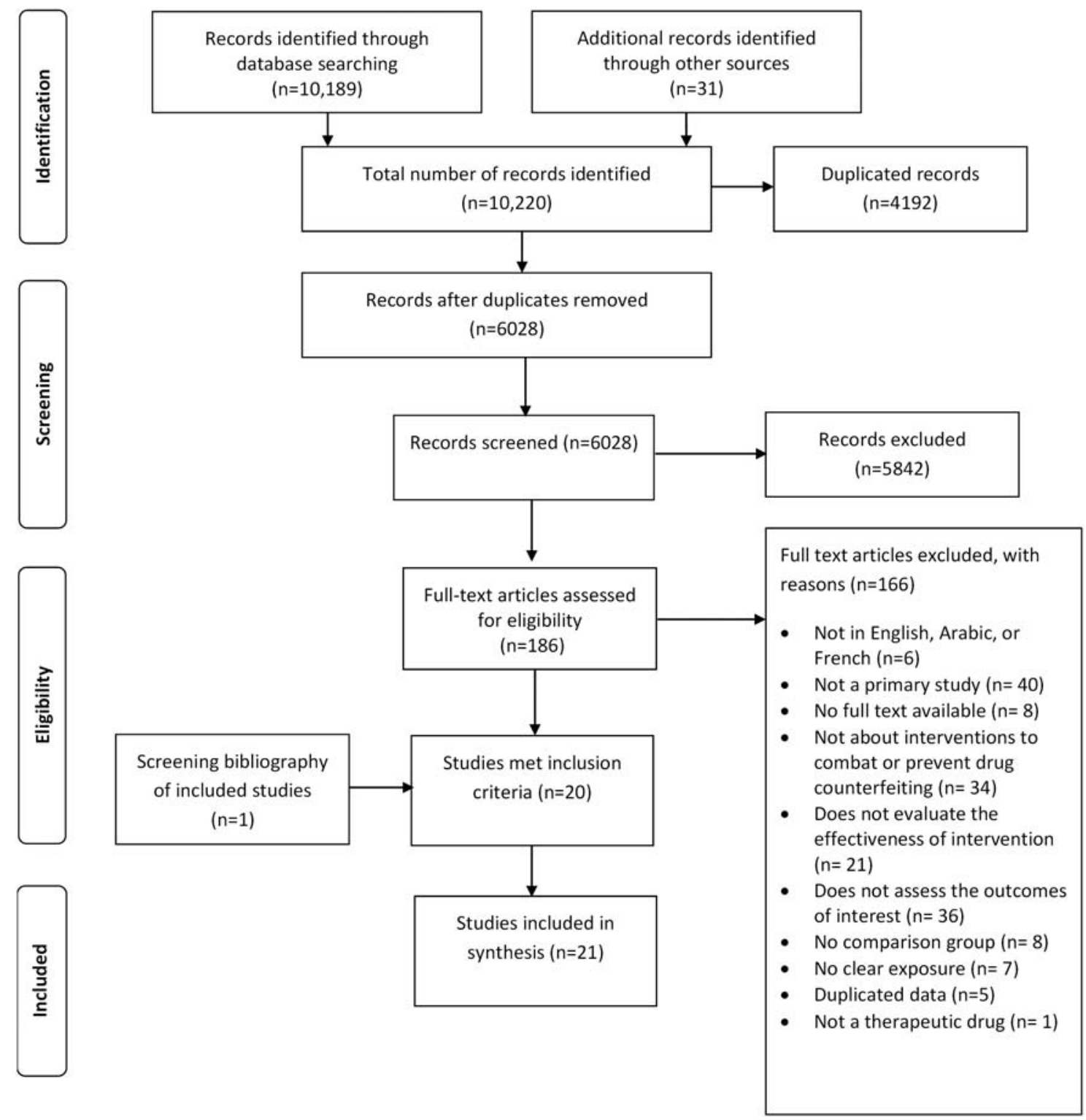

Figure 2 Flowchart for results of search strategy. 
Table 1 Key characteristics of the interventions included in the systematic review

\begin{tabular}{|c|c|c|}
\hline Intervention & Study design & Characteristics \\
\hline \multicolumn{3}{|c|}{ Laws and regulations (13 studies with 16 units of analysis) } \\
\hline Drug registration ${ }^{25-29}$ & $\begin{array}{l}5 \text { cross-sectional } \\
\text { studies }\end{array}$ & $\begin{array}{l}\text { A form of regulation to ensure access to effective and safe } \\
\text { medicines. It involves assessments by relevant drug regulatory } \\
\text { authorities of manufacturers of all components of drugs to } \\
\text { ensure they are certified as meeting the international standards } \\
\text { for GMP before authorising the drug for sale. }\end{array}$ \\
\hline $\begin{array}{l}\text { WHO-prequalification of } \\
\text { drugs }^{25} 3031\end{array}$ & $\begin{array}{l}3 \text { cross-sectional } \\
\text { studies }\end{array}$ & $\begin{array}{l}\text { A service provided by the WHO to "facilitate access to } \\
\text { medicines that meet unified standards of quality, safety and } \\
\text { efficacy primarily for HIV/AIDS, malaria TB and reproductive } \\
\text { health". }{ }^{31}\end{array}$ \\
\hline Licensing of drug outlet ${ }^{25} 2832-37$ & $\begin{array}{l}8 \text { cross-sectional } \\
\text { studies }\end{array}$ & $\begin{array}{l}\text { This refers to the authorisation of pharmaceutical establishments } \\
\text { by drug regulatory authorities with the aim of ensuring that the } \\
\text { supply and sale of drugs are carried out by qualified personnel } \\
\text { on premises that meet regulatory requirements. }\end{array}$ \\
\hline \multicolumn{3}{|l|}{ Technological innovations ( 1 study) } \\
\hline $\begin{array}{l}\text { Product authentication } \\
\text { technology } y^{38}\end{array}$ & $\begin{array}{l}1 \text { retrospective } \\
\text { study }\end{array}$ & $\begin{array}{l}\text { This involved the deployment of six handheld laser (Raman) } \\
\text { spectrometers by the National Agency for Food and Drug } \\
\text { Administration and Control for immediate authentication of drugs } \\
\text { at the point of sale. }\end{array}$ \\
\hline \multicolumn{3}{|c|}{ Awareness and communication (2 studies) } \\
\hline Increased public information ${ }^{24}$ & $\begin{array}{l}1 \text { cross-sectional } \\
\text { study }\end{array}$ & $\begin{array}{l}\text { A public awareness campaign, mainly using TV and radio } \\
\text { announcements, to promote public awareness of the dangers of } \\
\text { counterfeit medicine from the illicit drug market. The campaign } \\
\text { was designed based on previous survey data collected to } \\
\text { evaluate the purchasing practices of consumers. }\end{array}$ \\
\hline $\begin{array}{l}\text { Local and international } \\
\text { collaboration }^{39}\end{array}$ & 1 case study & $\begin{array}{l}\text { An international cross-disciplinary model of interaction and } \\
\text { collaboration between WHO officials, physicians, pharmacists } \\
\text { and scientists, and the Interpol, to investigate the source of } \\
\text { counterfeit drugs in South East Asia. }\end{array}$ \\
\hline \multicolumn{3}{|c|}{ Multifaceted interventions (5 studies with 6 units of analysis) } \\
\hline The PQM Program ${ }^{40-43}$ & 4 pre-post studies & $\begin{array}{l}\text { A mechanism for MQM funded by the USAID and implemented } \\
\text { by the USP. It is characterised by (1) early detection of } \\
\text { poor-quality medicines (substandard and counterfeit) using a } \\
\text { three-level testing approach of increasingly complex levels of } \\
\text { analysis, (2) collaborations with a country's medicine regulatory } \\
\text { authorities and international partners, and (3) strengthening of } \\
\text { regulatory authorities' capacities for enforcement of actions } \\
\text { based on field evidence. }\end{array}$ \\
\hline $\begin{array}{l}\text { Quality assurance system within } \\
\text { the NDPP }\end{array}$ & 1 pre-post study & $\begin{array}{l}\text { The system encompassed three main features: (1) development } \\
\text { of regulations, for example, improvement of drug registration } \\
\text { system and increased requirement for imported drugs, }(2) \\
\text { training of drug inspectors in good manufacturing and pharmacy } \\
\text { practice, and (3) implementation of legal actions, for example, } \\
\text { fines and product recall. }\end{array}$ \\
\hline $\begin{array}{l}\text { Regulatory intervention on private } \\
\text { pharmacy services }^{23}\end{array}$ & 1 randomised trial & $\begin{array}{l}\text { The regulatory interventions focused on improving the quality of } \\
\text { private pharmacy services. The regular intervention package } \\
\text { consisted of four high-quality annual inspections, sanctions for } \\
\text { any violation, distribution of regulation documents to the private } \\
\text { pharmacies and provision of information to the drug sellers } \\
\text { about particular areas needing improvement. The active } \\
\text { intervention package included these components, and was } \\
\text { actively promoted through intensified supervision and additional } \\
\text { training for the district drug inspectors. }\end{array}$ \\
\hline \multicolumn{3}{|c|}{$\begin{array}{l}\text { GMP, good manufacturing practice; MQM, Medicine Quality Monitoring; NDPP, National Drug Policy Programme; USAID, US Agency for } \\
\text { International Development; USP, US Pharmacopeia; TB, tuberculosis. }\end{array}$} \\
\hline
\end{tabular}


(19 studies); changes in prevalence of counterfeit drugs (4 studies); confiscation of counterfeit drugs (2 studies); closure of illegal outlets (2 studies); and changes in behaviour of consumers (1 study). Some studies reported more than one type of outcome. Most of the studies used failure rates to measure changes in the quality of medicines without distinguishing between counterfeit and substandard drugs.

\section{Risk of bias}

Online supplementary tables S3 and S4, respectively, show the assessments of the risk of bias for the observational studies and the single randomised trial. Online supplementary figures S1 and S2 show the corresponding risk of bias summary figures.

\section{Effects of interventions}

This section addresses the type and evidence for each intervention separately. We present the results of singleintervention studies in the order they appear in the framework followed by the multifaceted intervention studies that cut across the different elements in the framework.

\section{Registration}

Five cross-sectional studies examined the association between registration of medicines and changes in failure rates, and prevalence of counterfeit drugs. ${ }^{25-29}$ We were able to pool the results for four studies. The pooled association estimate was $\mathrm{OR}=0.23$ (95\% CI 0.08 to 0.67 ), with $\mathrm{I}^{2}$ of $88 \%$ (see online supplementary figure S3).

Of the four studies included in the meta-analysis, one conducted statistical tests and found a statistically significant association between drug registration and decreased prevalence of counterfeit drugs (adjusted $\mathrm{OR}=6.24, \mathrm{p}<0.05,95 \%$ CI 1.77 to 22.05$).{ }^{28}$ Only one report found a higher failure rate among registered medicines than unregistered medicines $(30 \%$ vs $20 \%$, respectively). ${ }^{25}$ Segregation of the results for this study by imported and local production status showed a higher failure rate among locally registered medicines than unregistered medicine ( $51 \%$ vs $18 \%$, respectively), with similar failure rates observed for imported medicines (23\% vs $26 \%$, respectively). We did not include the study by Bate $e t a l,{ }^{27}$ in the meta-analysis because it did not report the statistical data required to calculate the OR. The study found that drug registration remained strongly correlated with drugs passing the most stringent test even after adding city-fixed effects (ie, city-specific regulation enforcements such as maximum penalty, taxes and price regulations). The calculated marginal effect was $0.489(\mathrm{t}=7.844, \mathrm{p}<0.01)$.

\section{WHO-prequalification of drugs}

Three cross-sectional studies examined the association between WHO-prequalification of drugs and changes in failure rates. ${ }^{25} 30{ }^{31}$ We pooled all three studies in a meta-analysis. The overall result showed a statistically significant association between WHO-prequalification and decreasing failure rates among tested samples. The pooled association estimate was $\mathrm{OR}=0.06$ (95\% CI 0.01 to 0.35 ), with $\mathrm{I}^{2}$ of $78 \%$ (see online supplementary figure S4).

\section{Licensing of drug outlets}

Six cross-sectional studies examined the association of licensing of drug outlets on failure rates, ${ }^{25} 32-3537$ and another two examined such association on the prevalence of counterfeit drugs. ${ }^{28}{ }^{36}$ We were able to pool the results for four of the six studies that reported the outcomes as failure rates. ${ }^{25} 32 \quad 3537$ The overall result showed a non-statistically significant association of licensing of drug outlets on failure rates of medicines. The pooled association was $\mathrm{OR}=0.40$ (95\% CI 0.11 to 1.37$)$, with $\mathrm{I}^{2}$ of $86 \%$ (see online supplementary figure S5).

The pooled results for the two studies reporting on the prevalence of counterfeited drugs found a nonstatistically significant association between licensing of drug outlets and decreased prevalence of counterfeit drugs. The pooled association estimate was $\mathrm{OR}=0.66$ (95\% CI 0.41 to 1.05 ) with $\mathrm{I}^{2}$ of $0 \%$ (figure 3 ).

Of the eight included studies on licensing of drug outlets, three conducted statistical tests, and found no statistically significant association of licensing of drug outlets on failure rates ${ }^{33}$ and prevalence of counterfeit drugs. ${ }^{28}{ }^{36}$ Only 1 study (of 8 ) found a higher failure rate among licensed drug outlets compared to unlicensed drug outlets ( $34 \%$ vs $16 \%$, respectively). ${ }^{32}$

\section{Spectrometry technology}

Bate and Mathur ${ }^{38}$ conducted a retrospective study to assess the effects of deploying six hand-held laser Truscan (Raman) spectrometers at several inspection points. Samples were collected in 2007, 2009 and 2010, to compare the quality of drugs before and after the spectrometers were introduced in 2009. Minilab tests were used

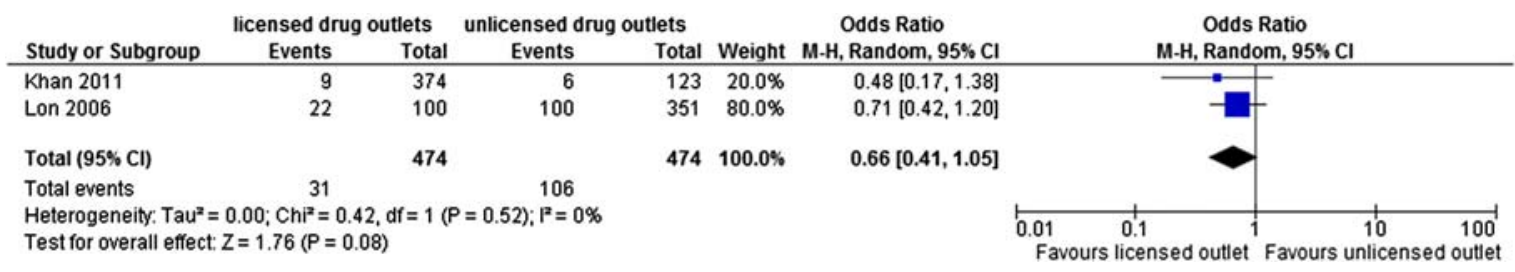

Figure 3 Forest plot for licensing of drug outlet intervention, outcome: prevalence of counterfeit drugs. 
to run semiquantitative thin-layer chromatography and disintegration tests, to determine the presence and relative concentration of active ingredients. This was followed by spectrometry testing to reflect on all the contents of the sample. The authors reported a significant increase in the number of drugs passing the minilab tests $(89 \%$ vs $81 \%$, respectively) and spectrometry tests $(88 \%$ vs $78 \%$, respectively) postintroduction of the spectrometers. Similarly, disaggregation of the results by drug type showed a higher percentage of samples passing each test postintroduction of the technology.

\section{Public awareness campaigns}

Abdoulaye $e t a l^{24}$ conducted a cross-sectional study to examine the association between a public awareness campaign on the dangers of counterfeit medicines from illicit drug markets and changes in the behaviour of consumers. The study found that $51.5 \%$ of households that previously bought medicines from street markets reported declining this practice. Specifically, respondents who received the awareness messages were six times more prone to divert from the illicit drug market than those who did not $(\mathrm{OR}=6.38,95 \%$ CI 1.9 to 21.37 $\mathrm{p}=0.0027)$. Those who received messages about the dangers of the street medicine market changed their behaviours $60.9 \%$ of the times against $22.2 \%$ for those who did not receive any message $(p=0.033)$. Those who received messages about the availability of cheaper medicine at the pharmacies and clinics stopped buying from the informal market $73.8 \%$ of the time compared with $51.2 \%$ for those who did not receive any message $(\mathrm{p}=0.003)$.

\section{Collaborative model}

A case study by Newton $e t a l^{39}$ examined an international cross-disciplinary model of collaboration in quantifying and identifying the source of the counterfeit antimalarial drug, artesunate, in South East Asia. Of the 391 samples of artesunate analysed, the investigators found 16 different fake hologram types. Chemical analysis detected a wide range of wrong active ingredients, including raw materials for the manufacture of methylenedioxymethamphetamine (ecstasy), which suggested the counterfeits may be coming from these factories. Biological analyses of pollen grains inside packages allowed investigators to trace the origin of some of the counterfeited artesunate to Southern China. These results stimulated the Chinese Government to act against the counterfeiters resulting in arrests, seizures and closure of illegal outlets. The model of collaboration was successful in the investigation of the problem of counterfeit artesunate in South East Asia.

\section{Multifaceted interventions}

Five studies (representing 6 units of analysis) examined the effects of multifaceted interventions on the prevalence of counterfeit and substandard drugs.

\section{Promoting quality of medicine (PQM) Program}

Four pre-post studies examined the effects of the PQM Program. ${ }^{40-43}$ Table 2 summarises the key findings from each study. In all four studies, PQM was implemented and expanded, in collaboration with the country's medicine regulatory authorities and other health entities. In Krech $e t a l,{ }^{41}$ the PQM Program was implemented alongside other interventions to combat poor-quality drugs.

\section{National Drug Policy Program (NDPP)}

Syhakhang $e t a t^{23}$ evaluated the impact of two different aspects of the National Drug Policy Program (NDPP). A pre-post study design evaluated the impact of implementing the Quality Assurance system, while a randomised trial evaluated two different levels of the regulatory interventions. The investigators found a statistically significant decrease in substandard drugs from $46 \%$ (169 of 366) to 22\% (66 of 300) between 1997 and 1999 $(\mathrm{p}<0.001)$. Samples with no active ingredients (likely to be counterfeited) decreased from $3.3 \%$ to $1 \%$ $(p=0.048)$. Samples with lower or higher content of active ingredient than approved limits decreased from $12 \%$ to $4 \% \quad(\mathrm{p}<0.001)$. Weight variations outside approved limits decreased from $35 \%$ to $14 \%(p<0.001)$. The randomised trial, which assessed the impact of regulatory intervention on private pharmacy services, found no statistically significant differences in the percentages of substandard drugs between the active and regular intervention pharmacies (25\% vs $20 \%$, respectively; $\mathrm{p}=0.215$ ).

\section{Assessment of the quality of evidence}

Within the individual observational studies, we judged the risk of biases associated with exposure and outcome measurements as generally low, and controlling for confounding variables as unclear. We judged the overall quality of evidence from observational studies as low due to study design. We also considered the presence of heterogeneity when we rated down the quality of evidence as a factor that limits our confidence in pooled effect estimate. ${ }^{44}$ The evidence for the randomisation trial was judged as moderate due to lack of blinding and insufficient information on allocation concealment. We were unable to assess publication and reporting biases due to the small number of studies, and the absence of published protocols, respectively. Although we had initially planned to construct funnel plots, we eventually opted against that since the number of included studies in the meta-analyses was fewer than 10 . Lau et $a t^{45}$ state that funnel plots are only encouraged for interventions that include at least 10 studies, with a substantially higher number in the presence of significant heterogeneity. ${ }^{22}$

\section{DISCUSSION}

While the findings of the systematic review provide valuable insights into policy and practice, the evidence base on the effectiveness of anticounterfeit drug interventions 
Table 2 A summary of the findings from the studies on the PQM Program*

\begin{tabular}{llll}
\hline Study & Country & Date of implementation & Key \\
\hline Krech et $a f^{41}$ & Cambodia & PQM was implemented in 2009
\end{tabular}

Key findings

Comparing the period from 2005-2008 with the period from 2009 onwards, there has been a statistically significant reduction in the failure rate from $3.8 \%$ (33 of $877,95 \% \mathrm{Cl} 2.7$ to 5.2 ) to $2.1 \%$ ( 73 of $3484,95 \% \mathrm{Cl}$ 1.7 to 2.6$)(p=0.0065)$. Twenty-eight counterfeit medicines were found from 2005-2009 and none were found from 2010-2012.

By the end of 2011, Cambodia had reportedly closed over $99 \%$ of illegal pharmacy outlets through the Inter-Ministerial Committee to Fight against Counterfeit and Substandard Medicines.

MOH FDD ${ }^{43} \quad$ (Lao PDR) PQM was implemented in 2005 and expanded from 2005-2009

$\mathrm{PQM}^{40} \dagger$

Southeast Asia

Pribluda et $a f^{42}$

Amazon Basin countries
The failure rates decreased from $3.2 \%$ in 2005 to $0.6 \%$ in 2009. During that same period, the number of samples tested increased from 158 in 2005 to 346 in 2009. The percentage of counterfeit drugs fluctuated on a year by year basis, with an initial rate of $2.5 \%$ (4 of 158 ) in 2005 and an average of $0.4 \%$ (6 of 1409) from 2006-2009.

Numerous confiscations, fines and arrests were also reported.

Thailand: The failure rate decreased from an initial $2.4 \%$ in 2005 to $1 \%$ in 2009.

Vietnam: While the initial failure was zero in 2005, the failure rate decreased from $2.3 \%$ in 2006 to $0.3 \%$ in 2009.

The Philippines: Statistical data were not available for the Philippines, but the authors reported that since the establishment of the PQM's MQM Program for tuberculosis medicine in 2009, "none of the anti-tuberculosis medicines tested within six months have been found to be substandard".

With the exception of two countries, the results for over 100 samples per country were submitted, and since 2008 "most indicated a significant decrease in the percentages that did not pass quality control testing (failures)".

For instance, in Brazil, 18.7\% (29 of 155) of samples tested in 2008 failed while none of the 60 samples tested in 2010 failed. In Ecuador, 25\% (18 of 72) of samples tested in 2008 failed in contrast to $0.81 \%$ (1 of 122) in 2010.

${ }^{*}$ For some of the above countries, more than one report was available for the PQM Program. We contacted the respective authors who advised us on the datasets to use to avoid overlaps and duplications.

†The results for Cambodia and Lao PDR were not included because they were captured in the studies by Krech et $a l^{41}$ and Ministry of Health's, Food and Drug Department, ${ }^{43}$ respectively.

MOH FDD, Ministry of Health's, Food and Drug Department; Lao PDR; Lao People's Democratic Republic; PQM, promoting quality of medicine.

is weak. Overall, we found low quality evidence suggesting that regulatory measures, specifically drug registration and WHO-prequalification of drugs, may be effective in reducing the prevalence of counterfeit and substandard drugs. The evidence for licensing of drug outlets suggests that by itself it is probably ineffective. For the remaining single interventions, which include the deployment of handheld spectrometry technologies at various inspection points and an international cross-disciplinary model of collaboration, very low quality evidence suggests they may be effective in decreasing the prevalence of counterfeit and substandard drugs. We also found very low quality evidence suggesting that a public awareness campaign on the danger of counterfeit medicine from illegal drug outlets may be effective in changing the purchasing practices of individuals. For multifaceted interventions (including a mix of regulations, training of inspectors, public-private collaborations and legal actions), low quality evidence suggests they may be effective in reducing the prevalence of substandard and counterfeit 
drugs. One randomised trial of moderate quality found no significant difference between the active intervention that involved two extra inspections (intensified supervision and additional training for the district drug inspectors) and the regular intervention in improving the quality of medicines.

We pooled the results separately for drug registration, WHO-prequalification and licensing of drug outlets, given their differing nature. With the exception of the meta-analysis on the association between licensing of drug outlets and prevalence of counterfeit drugs, we found significant heterogeneity for each of the remaining meta-analyses. We could not formally explore the potential sources of heterogeneity given the small number of included studies. Possible sources of heterogeneity may include variations across studies in the types of drugs evaluated and methods used to measure failure rate. The latter is plausible given the variety of instruments and pharmacopoeia standards used for assessment of failure rates.

While drug registration and WHO-prequalification of drugs appeared to be effective, the findings for drug registration highlighted the need for routine market surveillance and expansion of regulatory functions to cover local manufacturers and importers. For WHOprequalification of drugs, the quality of WHOprequalified medicines still varied depending on the country of procurement. One study found that China had the highest number of drugs of WHO-approved manufacturers that failed quality control testing, followed by India, with the lowest failure rates observed for WHO-prequalified drugs coming from the USA and European Union. ${ }^{30}$ Licensing of drug outlets alone appeared to be ineffective in reducing the prevalence of counterfeit and substandard drugs. This may likely be related to ineffective licensing systems and the absence of routine inspection of outlets.

We could only retrieve a single study for the remaining single interventions. The evidence on multifaceted interventions suggests they may be effective in reducing the prevalence of substandard and counterfeit drugs; however, it was difficult to single out the contributions made by the individual types of interventions. More so, poor quality medicines were still reported, necessitating the need for continuous monitoring and collaborations to combat the problem. The success of the PQM Program, in particular, required collaborations with medicine regulatory bodies, qualified personnel and political will, to act on findings.

Our systematic review did not identify eligible studies assessing other relevant types of interventions (see framework in figure 1). In particular, we could not identify primary studies assessing the effectiveness of anticounterfeit packaging and traceability technologies (barcoding and radiofrequency identification systems (RFID)) in reducing the prevalence of counterfeit drugs despite the fact that they have become prominent preventive measures in the fight against drug counterfeiting. ${ }^{16} 4647$
Existing systematic reviews focused mainly on the prevalence of counterfeit and substandard drugs ${ }^{13} 4849$ or on the risk factors and consequences of drug counterfeiting. ${ }^{50}$ One systematic review provided an overview of available analytical technologies for detecting counterfeit and substandard drugs, and compared their suitability in low-income and middle-income countries. ${ }^{51}$ Another systematic review focused on the RFID intervention, but it did not include any effectiveness studies. ${ }^{52}$

\section{Strengths and limitations}

To our knowledge, this is the first systematic review assessing the effectiveness of interventions to combat or prevent drug counterfeiting. We searched multiple databases and included the published as well as grey literature to increase the comprehensiveness of our search. We also conducted rigorous appraisals of included studies. In addition, our systematic review responds to a policy-relevant priority as identified by policymakers and stakeholders.

Some of the limitations relate to those of the included studies. We identified only one randomised trial of moderate quality. The observational studies suffered from risk of biases related to sampling methods and inadequate control for significant potential confounders. Also, for some interventions, only a single study was retrieved, limiting our ability to draw any conclusion regarding the effectiveness of the intervention. Most of the studies did not distinguish between counterfeit and substandard drugs, referring to changes in quality of medicines collectively as 'failure'. Only four studies 28293639 reported conducting some form of authentication investigation, which is important to confirm if a medicine is counterfeit, particularly since samples that have passed laboratory tests were still found to be counterfeit on investigation. ${ }^{29}$ Another limitation of the review may relate to the fact that we only included studies written in English, Arabic or French.

\section{Implications for policy}

Based on the current available evidence, government and regulatory agencies in low-income and middle-income countries may benefit from spending their resources on strengthening the registration procedure to ensure that all drugs, including those of domestic manufacturers and importers, are assessed for safety, quality and efficacy before they are released into the market. More importantly, they probably should complement drug registration with routine postmarketing surveillance to sustain the quality of drugs circulating in the market as well as maintain an updated published list of registered drugs.

Countries that rely heavily on imported drugs may consider opting for drugs that are WHO-prequalified. However, they should keep in mind that even among WHO-prequalified products, the quality of medicine may vary depending on the country of export. 
The three-level testing approach developed by the PQM Program can offer regulators in limited resource settings with a "cost-effective high-throughput methodology" for quality monitoring of drugs that produces valid and reliable results. ${ }^{53}$ The approach can strengthen drug quality assurance systems and ultimately reduce the prevalence of poor quality medicines.

While the evidence on licensing of drug outlets suggests it may not be effective by itself, policymakers may want to consider multifaceted interventions that include a mix of regulations, training of personnel, publicprivate collaborations and enforcement of legal actions.

\section{Implications for research}

There is still a dearth of methodologically rigorous studies to assess interventions to combat or prevent drug counterfeiting. Future research should produce effectiveness studies that address the methodological limitations of the available evidence. There should be more efforts made towards conducting well-designed randomised trials, quasi-experimental studies, and/or observational studies (eg, interrupted time series or pre-post studies with control groups). The latter should aim for proper assessment of exposures and outcomes, control for significant confounders and minimise selection biases.

Future studies should also evaluate other types of interventions such as packaging and traceability technologies, criminal enforcement laws, price control, as well as interventions that can improve the demand side. There is also a need to conduct cost-effectiveness studies on the different types of interventions at the country level.

Finally, there is a need to adopt a standard definition for what constitutes a counterfeit drug and develop standardised methodologies to minimise heterogeneity and allow comparison of interventions across different studies and settings.

\section{Author affiliations}

${ }^{1}$ Center for Systematic Review in Health Policy and Systems Research (SPARK), American University of Beirut, Beirut, Lebanon

${ }^{2}$ Faculty of Health Sciences, Department of Health Management and Policy, American University of Beirut, Beirut, Lebanon

${ }^{3}$ Department of Clinical Epidemiology and Biostatistics, McMaster University, Hamilton, Ontario, Canada

${ }^{4}$ Department of Internal Medicine, American University of Beirut, Beirut, Lebanon

${ }^{5}$ Faculty of Health Sciences, Department of Epidemiology and Population Health, American University of Beirut, Beirut, Lebanon

${ }^{6}$ Evidence for Policy and Practice Information and Coordination Centre, Social Science Research Unit, Institute of Education, London, UK

${ }^{7}$ Faculty of Public Health, Laboratory of Epidemiological and Clinical Research, Lebanese University, Beirut, Lebanon

${ }^{8}$ Department of Health Services Research, CAPHRI School for Public Health and Primary Care, Maastricht University, Maastricht, The Netherlands ${ }^{9}$ Saab Medical Library, American University of Beirut, Beirut, Lebanon ${ }^{10}$ Department of Health Education, Ministry of Public Health, Beirut, Lebanon

Contributors FE-J, EAA and RF were involved in the concept and design; $\mathrm{FE}-\mathrm{J}, \mathrm{EAA}, \mathrm{RF}, \mathrm{RH}, \mathrm{SO}$ were involved in the refinement of the review question and development of the eligibility criteria; FE-J, EAA, RF, SO were involved in the drafting of the protocol; AF and RF were involved in the search strategy design; AF was involved in the identification of relevant databases and grey literature; RF, LE-B, NS, RR were involved in the title and abstract screening full text screening, data abstraction and risk of bias assessment; FE-J, EAA, RF were involved in the data analysis; FE-J, EAA, RF, SO, RH were involved in the interpretation of the results; FE-J, EAA, RF, SO were involved in the drafting of the manuscript. All authors critically revised the manuscript and approved this final submitted version.

Funding This work was supported by The Alliance for Health Policy and Systems Research at the WHO, grant number 102716.

Competing interests None.

Provenance and peer review Not commissioned; externally peer reviewed.

Data sharing statement No additional data are available.

Open Access This is an Open Access article distributed in accordance with the Creative Commons Attribution Non Commercial (CC BY-NC 4.0) license, which permits others to distribute, remix, adapt, build upon this work noncommercially, and license their derivative works on different terms, provided the original work is properly cited and the use is non-commercial. See: http:// creativecommons.org/licenses/by-nc/4.0/

\section{REFERENCES}

1. Mackey TK, Liang BA. Improving global health governance to combat counterfeit medicines: a proposal for a UNODC-WHO-Interpol trilateral mechanism. BMC Med 2013;11:233.

2. World Health Organization. General information on counterfeit medicines. http://www.who.int/medicines/services/counterfeit/ overview/en/ (accessed 7 Mar 2014). Secondary World Health Organization. General information on counterfeit medicines.

3. [No authors listed]. Fighting fake drugs: the role of $\mathrm{WHO}$ and pharma. Lancet 2011;377:1626.

4. World Health Organization. Medicines: spurious/falsely-labelled/ falsified/counterfeit (SFFC) medicines. 2012. http://www.who.int/ mediacentre/factsheets/fs275/en/ (accessed 25 Mar 2014).

5. Putze E, Conway E, Reilly M, et al. The Deadly World of Fake Drugs. http://www.aei.org/files/2012/02/27/-appendix-a-master-2_ 170026856632.pdf (accessed 3 Apr 2014).

6. Faucon B. No cure for fake drugs. The Wall Street Journal 15 February 2010. http://online.wsj.com/news/articles/SB10001424052748 704533204575047282075703998 (accessed 3 April 2014).

7. Liberman J. Combating counterfeit medicines and illicit trade in tobacco products: minefields in global health governance. J Law Med Ethics 2012;40:326-47.

8. Degardin K, Roggo Y, Margot P. Understanding and fighting the medicine counterfeit market. J Pharm Biomed Anal 2014;87:167-75.

9. Newton PN, Amin AA, Bird C, et al. The primacy of public health considerations in defining poor quality medicines. PLoS Med 2011;8: e1001139.

10. World Health Organization. Substandard/spurious/falsely-labelled/ falsified/counterfeit medical products: report of the Working Group of Member States. 2012. http://apps.who.int/gb/ebwha/pdf_files/ WHA65/A65_23-en.pdf (accessed 20 Mar 2014).

11. Attaran A, Barry D, Basheer S, et al. How to achieve international action on falsified and substandard medicines. BMJ 2012;345: e7381.

12. Liang BA. Fade to black: importation and counterfeit drugs. $A m$ Law Med 2006;32:279-323.

13. Kelesidis T, Kelesidis I, Rafailidis PI, et al. Counterfeit or substandard antimicrobial drugs: a review of the scientific evidence. $J$ Antimicrob Chemother 2007;60:214-36.

14. Cockburn R, Newton PN, Agyarko EK, et al. The global threat of counterfeit drugs: why industry and governments must communicate the dangers. PLoS Med 2005;2:e100.

15. World Health Organization. Counterfeit medicines. 2006. http://www. who.int/medicines/services/counterfeit/impact/ImpactF_S/en/ (accessed 21 Nov 2014).

16. World Health Organization. Counterfeit drugs kill! 2008. http://www. who.int/impact/FinalBrochureWHA2008a.pdf (accessed $28 \mathrm{Mar}$ 2014).

17. Bansal D, Malla S, Gudala K, et al. Anti-counterfeit technologies: a pharmaceutical industry perspective. Sci Pharm 2013;81:1-13.

18. Bigdeli M, Javadi D, Hoebert J, et al., Alliance for Health Policy and Systems Research Network of Researchers on Access to Medicines. Health policy and systems research in access to medicines: a prioritized agenda for low- and middle-income countries. Health Res Policy Syst 2013;11:37. 
19. World Health Organization. Medicines: spurious/falsely-labelled/ falsified/counterfeit (SFFC) medicines. Fact sheet N 275. 2012. http://www.who.int/mediacentre/factsheets/fs275/en/

20. Higgins J, Green S. Cochrane Handbook for Systematic Reviews of Interventions Version 5.1.0 [updated March 2011]. The Cochrane Collaboration, 2011. http://handbook.cochrane.org/ (accessed $8 \mathrm{Apr}$ 2014).

21. Borenstein M, Hedges LV, Higgins JPT, et al. A basic introduction to fixed-effect and random-effects models for meta-analysis. Res Synth Method 2010;1:97-111.

22. Sterne JA, Sutton AJ, loannidis JP, et al. Recommendations for examining and interpreting funnel plot asymmetry in meta-analyses of randomised controlled trials. BMJ 2011;343:d4002.

23. Syhakhang L, Lundborg CS, Lindgren B, et al. The quality of drugs in private pharmacies in Lao PDR: a repeat study in 1997 and 1999. Pharm World Sci 2004;26:333-8.

24. Abdoulaye I, Chastanier $\mathrm{H}$, Azondekon A, et al. Evaluation of a public awareness campaigns on counterfeit medicines in Cotonou Benin. Med Trop (Mars) 2006;66:615-18.

25. World Health Organization. Survey of the quality of selected antimalarial medicines circulating in six countries of sub-Saharan Africa 2011 Jan. http://apps.who.int/medicinedocs/documents/ s19053en/s19053en.pdf (accessed 21 Mar 2014).

26. Bate R, Jensen $\mathrm{P}$, Hess $\mathrm{K}$, et al. Substandard and falsified anti-tuberculosis drugs: a preliminary field analysis. Int $J$ Tuberc Lung Dis 2013;17:308-11.

27. Bate $\mathrm{R}$, Jin $\mathrm{GZ}$, Mathur $A$. Does price reveal poor-quality drugs? Evidence from 17 countries. J Health Econ 2011;30:1150-63.

28. Khan $\mathrm{MH}$, Okumura J, Sovannarith $\mathrm{T}$, et al. Counterfeit medicines in Cambodia-possible causes. Pharm Res 2011;28:484-9.

29. Wondemagegnehu E. Counterfeit and Substandard Drugs in Myanmar and Viet Nam. 1999. http://apps.who.int/medicinedocs/pdf/ s2276e/s2276e.pdf (accessed 24 Apr 2014).

30. Bate R, Hess $\mathrm{K}$. The role of pre-shipment batch testing in ensuring good medicine quality. Malar World J 2012;3. http://www.aei.org/wpcontent/uploads/2012/12/-bate-the-role-of-preshipment-batch-testingin-ensuring-good-medicine-quality_12150071370.pdf

31. World Health Organization. Survey of the quality of anti-tuberculosis medicines circulating in selected newly independent states of the former Soviet Union. November 2011. http://apps.who.int/ medicinedocs/documents/s19053en/s19053en.pdf?ua=1 (accessed 23 Apr 2014).

32. Evans L, III, Coignez V, Barojas A, et al. Quality of anti-malarials collected in the private and informal sectors in Guyana and Suriname. Malar J 2012;11:203.

33. Hadi U, van den Broek P, Kolopaking EP, et al., Study Group Antimicrobial Resistance in Indonesia: Prevalence and Prevention AMRIN. Cross-sectional study of availability and pharmaceutical quality of antibiotics requested with or without prescription (Over The Counter) in Surabaya, Indonesia. BMC Infect Dis 2010;10:203.

34. Phanouvong S, Raymond C, Krech L, et al. The quality of antimalarial medicines in western Cambodia: a case study along the Thai-Cambodian border. Southeast Asian J Trop Med Public Health 2013;44:349-62.

35. Tipke M, Diallo S, Coulibaly $B$, et al. Substandard anti-malarial drugs in Burkina Faso. Malar J 2008;7:95.

36. Lon CT, Tsuyuoka R, Phanouvong S, et al. Counterfeit and substandard antimalarial drugs in Cambodia. Trans $R$ Soc Trop Med Hyg 2006;100:1019-24.
37. USP Drug Quality and Information Program. Survey of the Quality of Selected Antimalarial Medicines Circulating in Madagascar, Senegal, and Uganda, 2010. http://docs.mak.ac.ug/reports/surveyquality-selected-antimalarial-medicines-circulating-madagascarsenegal-and-uganda (accessed 27 Feb 2014).

38. Bate R, Mathur A. The impact of improved detection technology on drug quality: a case study of Lagos, Nigeria. AEI Economic Policy Working Paper, 2011. http://www.aei.org/wp-content/uploads/2011/ 10/Nigeria-Working-Paper-v1.pdf (accessed 2 Apr 2014).

39. Newton PN, Fernandez FM, Plancon A, et al. A collaborative epidemiological investigation into the criminal fake artesunate trade in South East Asia. PLoS Med 2008;5:e32.

40. Promoting the Quality of Medicines Program. Strengthening national capacity in medicines quality: five-year summary (2005-2009) promoting the quality of medicines program in Southeast Asia and the Philippines. Rockville, MD: The United States Pharmacopeial Convention, 2010. http://www.usp.org/worldwide/dqi/resources/ technicalReports.html (accessed 24 Mar 2014).

41. Krech LA, Barlow CL, Siv L, et al. Cambodian ministry of health takes decisive actions in the fight against substandard and counterfeit medicines. Trop Med Surg 2014;2. http://esciencecentral. org/journals/cambodian-ministry-of-health-takes-decisive-actions-inthe-fight-against-substandard-and-2329-9088.1000166.pdf

42. Pribluda VS, Barojas A, Anez A, et al. Implementation of basic quality control tests for malaria medicines in Amazon Basin countries: results for the 2005-2010 period. Malar J 2012;11: 202.

43. Ministry of Health, Food and Drug Department (MOH, FDD). Country Report on Medicines Quality Monitoring Program in Laos (20052009). 2010. http://www.usp.org/app/worldwide/medQualityDatabase/ download.php?id=20 (accessed 24 Mar 2014).

44. Guyatt GH, Oxman AD, Kunz R, et al. GRADE guidelines: 7. Rating the quality of evidence-inconsistency (accessed 23 Nov 2014). $J$ Clin Epidemiol 2011;64:1294-302.

45. Lau J, loannidis JP, Terrin N, et al. The case of the misleading funnel plot. BMJ 2006;333:597-600.

46. World Health Organization. Growing threat from counterfeit medicines. Bull World Health Organ 2010;88:247-8.

47. Williams A. Europe prepares to battle the counterfeiters. Pharm Technol Eur 2011;23:9-11.

48. Almuzaini T, Choonara I, Sammons H. Substandard and counterfeit medicines: a systematic review of the literature. BMJ Open 2013;3: e002923.

49. Nayyar GM, Breman JG, Newton PN, et al. Poor-quality antimalarial drugs in southeast Asia and sub-Saharan Africa. Lancet Infect Dis 2012;12:488-96.

50. Karunamoorthi $\mathrm{K}$. The counterfeit anti-malarial is a crime against humanity: a systematic review of the scientific evidence. Malar $J$ 2014;13:209.

51. Kovacs S, Hawes SE, Maley SN, et al. Technologies for detecting falsified and substandard drugs in low and middle-income countries. PLOS ONE 2014;9:e90601.

52. Coustasse A, Arvidson C, Rutsohn P. Pharmaceutical counterfeiting and the RFID technology intervention. J Hosp Mark Public Relations 2010;20:100-15.

53. Pribluda VS, Barojas A, Coignez V, et al. The three-level approach: a framework for ensuring medicines quality in limited-resource countries. Pharmaceut Reg Affairs 2014; 3:117. 